\title{
Influences of Environmental Chemicals on Atopic Dermatitis
}

\author{
Kwangmi Kim \\ College of Pharmacy, Dankook University, Cheonan, Korea
}

(Received May 23, 2015; Revised June 12, 2015; Accepted June 22, 2015)

\begin{abstract}
Atopic dermatitis is a chronic inflammatory skin condition including severe pruritus, xerosis, visible eczematous skin lesions that mainly begin early in life. Atopic dermatitis exerts a profound impact on the quality of life of patients and their families. The estimated lifetime prevalence of atopic dermatitis has increased 2 3 fold during over the past 30 years, especially in urban areas in industrialized countries, emphasizing the importance of life-style and environment in the pathogenesis of atopic diseases. While the interplay of individual genetic predisposition and environmental factors contribute to the development of atopic dermatitis, the recent increase in the prevalence of atopic dermatitis might be attributed to increased exposure to various environmental factors rather than alterations in human genome. In recent decades, there has been an increasing exposure to chemicals from a variety of sources. In this study, the effects of various environmental chemicals we face in everyday life - air pollutants, contact allergens and skin irritants, ingredients in cosmetics and personal care products, and food additives - on the prevalence and severity of atopic dermatitis are reviewed.
\end{abstract}

Key words: Atopic dermatitis, Air pollutants, Contact allergens, Skin irritants, Cosmetic ingredients, Food additives

\section{INTRODUCTION}

Atopic dermatitis (AD) is a common, chronic, relapsing, inflammatory skin condition that mainly occurs in children. $\mathrm{AD}$ normally begins early in life and often occurs in people with a personal or family history of asthma and allergic rhinitis (1). Most cases of $\mathrm{AD}$ develop in infants and young children, $60 \%$ occurring during the first year of life and up to $85 \%$ occurring before the age of 5 years (2). Most cases of childhood $\mathrm{AD}$ show improvement by adolescence $(3,4)$. However, in elderly adults with $\mathrm{AD}$, various symptoms of eczema exist during the lifetime and recurrence of eczema after many years is common $(5,6)$. Although the typical symptoms of $\mathrm{AD}$ vary with age of patients, they include severely pruritic, xerotic, and visible eczematous skin lesions mainly in flexural regions (7).

$\mathrm{AD}$ causes physical and emotional distress for patients

Correspondence to: Kwangmi Kim, College of Pharmacy, Dankook University, 119, Dandae-ro, Dongnam-gu, Cheonan-si, Chungnam 330-714, Korea

E-mail: booksto@dankook.ac.kr

This is an Open-Access article distributed under the terms of the Creative Commons Attribution Non-Commercial License (http:// creativecommons.org/licenses/by-nc/3.0) which permits unrestricted non-commercial use, distribution, and reproduction in any medium, provided the original work is properly cited. and their families. Especially, $\mathrm{AD}$ can have a profound impact on the quality of life of pediatric patients (8-10). Agonizing pruritus accompanying consecutive loss of sleep and concentration results in disrupted school performance, social activities, and participation in sports and visible skin lesions may cause the social stigmatization such as peer rejection, teasing, and bullying $(8,9)$. In addition, parents of pediatric patients of $\mathrm{AD}$ report loss of sleep, stress, and loss of leisure time (10).

The estimated lifetime prevalence of $\mathrm{AD}$ is $10 \sim 20 \%$ in children and $1 \sim 3 \%$ in adults while the world-wide incidence of $\mathrm{AD}$ has increased 2 3 fold over the past 30 years (11-13). It is noteworthy that the prevalence of $\mathrm{AD}$ in rural areas is significantly lower compared to that of urban area, emphasizing the importance of life-style and environment in the mechanisms of atopic diseases (14). Theories to explain this rise in $\mathrm{AD}$ include an increase in exposure to air pollution and allergens (15).

The skin of $\mathrm{AD}$ patients is different from healthy skin. $\mathrm{AD}$ is characterized by skin barrier abnormalities and complex immune dysregulation (16). Altered lipid synthesis, reduced hydration, decreased epidermal differentiation and infiltration of $\mathrm{T}$ cells have been described as characteristic features in the skin of AD patients (17). In addition, cytokine and chemokine genes consistent with allergic inflammation are upregulated in $\mathrm{AD}$ skin (17). The acute phase of 
$\mathrm{AD}$ is dominated by activation of $\mathrm{T}$ helper type (Th) 2 cells, while induction of IgE production and Th1, Th17, and Th22 cytokine responses of delayed hypersensitivity are more dominant in the chronic phase $(18,19)$. Foods, environmental airborne allergen, products of infectious pathogens, and skin proteins released by scratching can induce allergenspecific IgE antibodies in $\mathrm{AD}$ patients (20).

While the underlying mechanisms in pathogenesis of $\mathrm{AD}$ are not fully understood, it is generally accepted that the interplay of individual genetic predisposition and environmental factors contribute to the development of AD (2123). Since the world-wide incidence of $A D$ has markedly increased in recent years especially in urban areas, it is acceptable that this increase in the prevalence of $\mathrm{AD}$ is attributed to increased exposure to various environmental factors rather than alterations in human genome.

We may encounter millions of chemical compounds in lifetime. In recent decades, there has been an increasing exposure to chemical allergens from a variety of sources especially in industrialized countries (24-26). Some of them are released in our environment as exhaust fumes of cars, industrial dust, pesticides, fertilizers, insecticides, and smoke of tobacco. In addition, most of personal hygienic care products, cosmetics, processed foods, and drugs contain preservatives, pigments, fragrances, surfactants, chelating agents, and taste enhancers. Heavy metals could be released from amalgam fillings, dental implants, prosthetic devices, and jewelry. Such exposures to environmental triggers could influence the immune system during its development and specifically affect the balance between Th1 and Th2 responses. McFadden et al. proposed that the significant increase in the prevalence of $\mathrm{AD}$ and allergy seen in industrialized countries during the last five decades may be related with increased exposure to chemical allergens that favors the development of Th2-type responses, at least in part (24-26).

Air pollutants. In recent decades, air pollution has been regarded as an important extrinsic, environmental degrading etiologic agent. The severity of air pollution, particularly by combustion of engines, industrial factories, and heating systems in buildings, has been associated with the greater prevalence of allergic diseases in industrialized countries. Several epidemiological studies suggest a number of air pollutants have been considered responsible for the development or exacerbation of $\mathrm{AD}$ and other allergic diseases (27). The route of exposure to air pollutants is mainly through inhalation, ingestion, and skin contact. The main mechanisms by which these air pollutants enhance allergic responses are the adsorption of aeroallergens and a decrease in mucociliary activity with an increase in respiratory epithelial permeability to allergens. As a result, exposure to air pollution is revealed as a significant risk factor for the development of allergic disease such as asthma (28-
30). It is suggested that many air pollutants modify innate and acquired immune responses and that susceptibility to allergic diseases can vary with age, other modifying factors, and additional exposures. Actually a questionnairebased study of over ten thousands of swedish adults showed increased risk estimates for living close to heavy traffic and eczema (31).

Air pollutants consist of a number of substances in the air that can have hazardous effects on human health. They exist in either particulate or gaseous form and are classified as primary or secondary pollutants depending on their sources of occurrence. Major primary pollutants include sulfur oxide compounds, nitrogen oxide compounds, carbon monoxide, volatile organic compounds, particulate matter (PM), toxic metals, and radioactive pollutants. Secondary pollutants are formed from primary pollutants in the atmosphere through chemical and photochemical reactions. Secondary pollutants include ground level ozone, nitrogen dioxide, sulfuric acid, and smog.

A number of cross-sectional studies revealed an association between exposure to air pollutants and eczema symptoms. In a study, eczema symptoms were significantly associated with benzene, PM10, nitrogen oxide compounds, and $\mathrm{CO}$ exposure in 9- to 11-year-old children (32). In Taiwan, a nation-wide survey involving over 30 thousands of children demonstrated that flexural eczema was positively associated with exposure to traffic-related air pollutants (33). A birth cohort study in an urban area showed strong positive relationships between the distance to the nearest main road and eczema, while $\mathrm{NO}_{2}$ exposure was positively associated with eczema (34). Several studies have shown that outdoor air pollution influences the prevalence of AD. In a study involving 4907 French children, the lifetime prevalence of $\mathrm{AD}$ eczema was significantly associated with 3-year averaged concentrations of PM10, nitrogen oxide compounds, and CO (35). In the urban US birth cohort study, exposure to butyl benzyl phthalate during pregnancy was associated with eczema development at 2 years of age (36). These studies suggest that outdoor air pollution is one of potent risk factors for the development of $\mathrm{AD}$.

As well as the effects on the prevalence of $\mathrm{AD}$, outdoor air pollution influences the skin symptoms in $\mathrm{AD}$ patients. In a prospective study, the concentrations of outdoor PM10, PM2.5, toluene, and total volatile organic compounds were higher on days when the patients had symptoms of AD than on days when they reported no symptoms (37). PM is a mixture of solid and liquid particles of different origin with various chemical and physical properties, including pollen grains and mold spores. It is classified based on size, which determines the location where the particles can be deposited in the human body. For example, particulate matter with a diameter of $10 \mu \mathrm{m}$ or less is named as PM10 and particulate matter with a diameter of $2.5 \mu \mathrm{m}$ or less is 
names as PM2.5. Diesel exhaust particulate (DEP) accounts for most of the airborne PM in the atmosphere in large cities. In a study, an increased concentration of outdoor PM10 by $1 \mu \mathrm{g} / \mathrm{m}^{3}$ was significantly associated with a $0.44 \%$ increase in $\mathrm{AD}$ symptoms on the following day (37). The effect of PM on $\mathrm{AD}$ was also investigated in a study of 41 school children aged between 8 to 12 years (38). In this study, daily symptom scores and daily PM concentrations were measured. The results showed that the pruritus score was significantly associated with the concentrations of PM with a diameter less than $0.1 \mu \mathrm{m}$ but not for larger particles (38).

Benzene exerts multiple effects after being converted to reactive metabolites such as hydroquinone and benzoquinone. Benzene and its metabolites can influence the responses of mast cells and basophils together with other cells, such as $\mathrm{T}$ cells, macrophages, and monocytes (39). In a study performed on a group of 3-year-old children, it was observed that the exposure to benzene, ethylbenzene, and chlorobenzene was related with higher percentages of IL-4 producing $\mathrm{CD}^{+} \mathrm{T}$ cells. Both an increase in IL-4 producing Th2 cells and a reduction of IFN- $\gamma$ producing Th1 cells may contribute to increase in type 2 responses to allergens that favor the development of acute $\mathrm{AD}(40)$. It was reported that the benzene metabolites, such as catechol, hydroquinone, 1,2,4benzenetriol, and 1,4-benzoquinone, increased secretion of Th2-type cytokines IL-4 (41). Actually, a study revealed that a 1-ppb increase in benzene concentration was associated with a $27.38 \%$ increase in AD symptoms (37).

Several studies investigated the effects of other gaseous air pollutants such as formaldehyde, $\mathrm{NO}_{2}$, and volatile organic compounds on aggravation of $\mathrm{AD}$ symptoms. In a study performed on adults with $\mathrm{AD}$ and control, subjects were exposed to formaldehyde, $\mathrm{NO}_{2}$, or room air, the results showed that exposure to formaldehyde and $\mathrm{NO}_{2}$ increased transepidermal water loss in patients with $\mathrm{AD}$, whereas exposure to room air did not (42). The effect of volatile organic compounds on the skin of adults with $\mathrm{AD}$ and 12 healthy control subjects was examined. It was found that volatile organic compounds increased transepidermal water loss in patients with AD after 48 hours exposure, suggesting that skin barrier function in patients with $\mathrm{AD}$ is impaired by exposure to volatile organic compounds (43).

In addition to outdoor environments, indoor environments also contain air pollutants from various sources that include furniture, tobacco smoke, air conditioners, stoves, wall paints, construction materials, cloths, duvets, carpets, and human body itself. Concerns regarding indoor air pollution are increasing because people spend most of their time in their homes, schools, and public buildings. Indoor air pollutants include volatile organic compounds, PM, and combustion pollutants, such as sulfur dioxide, $\mathrm{CO}$, and $\mathrm{NO}_{2}$. In German birth cohort study, redecorating activities, such as painting, floor covering, and new furniture, before birth and in the first year of life were associated with the development of $\mathrm{AD}$ during the study period of 6 years (44). In another study in Asian children, authors found an association between $\mathrm{AD}$ severity and indoor home remodeling activities, such as painting, floor covering, and wallpapering (45). In this context, it is reasonable that a history of living in a newly built house during the first year of life was positively correlated with $\mathrm{AD}$ in school children (46). In a case-control study comprising 198 cases and 202 control subjects aged 3 to 8 years, eczema symptoms in children were associated with the concentration of butyl benzyl phthalate in dust collected from their bedrooms (47).

Tobacco smoke has been the special focus of interest as a potential trigger of allergic diseases. Number of chemicals included in tobacco smoke are widely accepted to be related with various diseases. As for $\mathrm{AD}$, prenatal exposure to environmental tobacco smoke is likely to induce a Th2-dominant immune status or the development of $\mathrm{AD}$ after birth (48-52). A study of 7030 children aged 6 to 13 years demonstrated a positive correlation between $\mathrm{AD}$ and maternal smoking during pregnancy, in the first year after birth, or both (53). In another study, prenatal exposure to PM2.5 in combination with postnatal exposure to tobacco smoke increased the risk of eczema in infants (54). In addition, one recent study on air pollution indicated that PM and polycyclic aromatic hydrocarbons influence the early and late gestation with lymphocyte cell distribution (55).

On the other hand, it is interesting that personal susceptibility to the hazardous air pollution and its clinical consequences can be modified by the presence of atopy or other allergic diseases. A study about the northeast Chinese children health of more than 30 thousands children clearly showed that the modification by atopy, which examined associations by using multipollutant (PM, sulfur dioxide, $\mathrm{NO}_{2}, \mathrm{O}_{3}$, and carbon monoxide) models (56). In addition, a number of animal and human experimental model showed the upregulation of Th2 cytokine or IgE levels after exposure to air pollutant such as diesel exhaust, $\mathrm{NO}_{2}$, and polycyclic aromatic hydrocarbons $(57,58)$.

Collectively, these studies suggest that indoor or outdoor, gaseous or particulate forms of air pollutants are potential risk factors for the development or exacerbation of $\mathrm{AD}$.

Contact allergens and skin irritants. $\mathrm{AD}$ is aggravated by skin contact with chemical or physical irritants, such as excessive washing, soaps, and detergents (15). It is generally accepted that $\mathrm{AD}$ and allergic contact dermatitis shares similar pathogenesis and clinical symptoms. The clinical spectrum of Allergic contact dermatitis is characterized by itching, scaling, erythema, vesiculation, fissuring, hyperkeratosis and lichenification. In addition, allergic contact dermatitis to environmental chemicals typically develops following repeated topical exposure to chemical allergens and is characterized by the specific $\mathrm{T}$ lymphocyte 
responses (59).

Allergic contact dermatitis is a frequent and chronic skin disease, very often associated with environmental factors, mainly of occupational origin. So far, more than 3,700 compounds have been identified as contact allergens in the human environment. In North America and Western Europe, $12.5 \% \sim 40.6 \%$ of the population is diagnosed as allergic to at least one chemical (60).

One of the most important contact allergens are metals. Nickel, cobalt, and chromium are considered as the most common metals eliciting contact allergic dermatitis reactions from chronic internal exposure, although other metal ions could cause hypersensitivity reactions (61). In recent years, more and more researches report about the relevance of heavy metal burden (cadmium, lead, platinum, copper) to allergic responses $(62,63)$. Several literature data suggests that important, possible sources of sensitization to metals are metal implants used in various medical purposes, such as intravascular stents, dental implants, cardiac pacemakers, or implanted gynaecologic devices. Although skin hypersensitivity reactions to metals vary patient to patient, they include eczematous, urticarial, bullous, vasculitic eruptions, and inflammation, similar to those of $\mathrm{AD}(64,65)$.

Among the metals, mercury has drawn a special interest. The most important mercury sources are amalgam fillings in decayed teeth, additive in drugs, entrails, and fish-rich food. Mercury possesses an affinity for the epithelial cells of the gastrointestinal tract and the skin, for hair, thyroid gland, liver, pancreas, kidneys and the brain (66-68). However, the clinical relevance of exposure to mercury for the pathogenesis of $\mathrm{AD}$ is still controversial.

Ingredients in cosmetics and personal care products. Cosmetics, fragrances, and botanicals are also important causes of both irritant and allergic contact dermatitis. Although the overall incidence of dermatitis produced by cosmetics is rather difficult to determine, fragrances found in various types of cosmetics are important sources of allergic contact dermatitis. Fragrances, including fragrance mix, balsam of Peru, and cinnamic aldehyde, are the most commonly identified allergens in cosmetic-induced contact hypersensitivity reactions (69-71).

Preservatives which are added to the cosmetic products to prevent deterioration of cosmetics are another important trigger of allergic contact dermatitis. So far, a number of preservatives used in cosmetics have been described as eliciting contact dermatitis in sensitive consumers: parabens, isothiazolinones, formaldehyde and formaldehyde releasers, iodopropynyl butylcarbamate, and methyldibromo glutaronitrile (72).

Other important triggers of allergic contact dermatitis include the active ingredients in hair- and nail-care products, such as permanent wave solutions, permanent hair coloring, artificial nails and nail polishes (70). An important and potent contact allergen which has lately gained value is paraphenylenediamine. Paraphenylenediamine found in hair dye and temporary skin tattoos is also identified as a contact allergen (71).

Food additives. Although food as a factors for $\mathrm{AD}$ have long been subject of debate, but now it is generally accepted that food allergens are important factors of $\mathrm{AD}$ particularly in children (73-75). AD and food allergy commonly co-exist with severe and persistent AD, particularly in those with early onset (76). Both ingestion of food as well as epicutaneous food application are capable of inducing eczematous skin lesions. At least five foods - eggs, milk, soy, peanut, and wheat - are defined to be responsible for development of AD (77).

Besides food itself, several chemical substances added to food to improve its organoleptic properties may be associated with non-allergic food hypersensitivity. Food additives are added to food at any stage of its production, processing, treatment, packaging, transportation, or storage. Various food preservatives (parabens, benzoates, citric acid, nitrates and nitrites, sorbic acid, sulfiting agents), antioxidants (butylated hydroxyanisole, butylated hydroxytoluene), artificial dyes (tartrazine, erythrosine, sunset yellow, brilliant black), stabilizers (EDTA, carrageenan, guar), flavorings and taste enhancers (monosodium glutamate), emulsifiers (Arabic gum, karaya gum, lecithin, propylene glycol), and artificial sweeteners (aspartame, saccharin) were studied related with hypersensitivity reactions $(78,79)$.

Despite the increased use of food additives, the prevalence of adverse reactions attributed to their use is very low in the general population but seems higher in $\mathrm{AD}$ patients. In a large British survey of more than 15,000 individuals, the estimated prevalence of self-reported adverse reactions

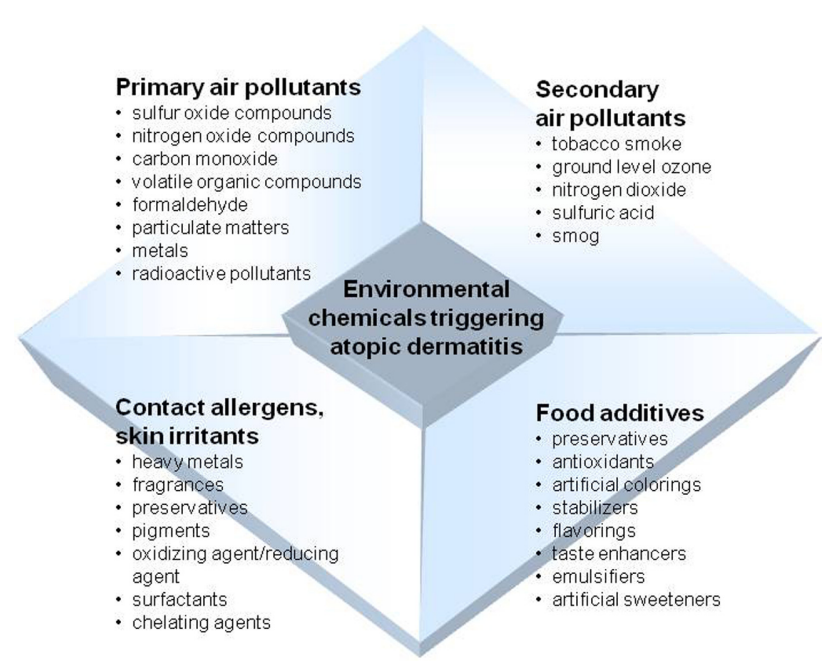

Fig. 1. Environmental chemicals related to development and severity of atopic dermatitis. 
to food additives was only $0.01 \sim 0.23 \%$ (80). Studies performed on atopic children reported the prevalence of adverse reactions to food additives at $1 \sim 2 \%$ (81) to $2 \sim 7 \%$ challenge (82). On the other hand, in 54 patients with various allergic diseases and suspected of having reactions to food additives, double-blind challenge testing with seven common additives - amaranth, erythrosine, tartrazine, sunset yellow, sodium sulfite, sodium benzoate, and monosodium glutamate-showed no statistically significant difference between food additives and placebo (83). The results showed that 5 patients $(9.3 \%)$ had a positive reaction to food additives but no reactions to the placebo, 2 patients $(3.7 \%)$ reacted to both food additives and to the placebo, 3 patients $(5.5 \%)$ reacted to the placebo only, and the remaining 44 patients $(81.5 \%)$ reacted to neither. Statistically significant difference was not observed between those who reacted positively to food additives and those who reacted positively to the placebo (83).

\section{CONCLUSION}

In this study, we reviewed the effects of various environmental chemicals on the prevalence and severity of AD. Regarding air pollutant, a number of air pollutants - either particulate or gaseous form, indoor or outdoor - have been found to be related with the prevalence, development or exacerbation of $\mathrm{AD}$. Those air pollutant chemicals include nitrogen oxide compounds, PM, CO, toluene, volatile organic compounds, benzene and its metabolites, formaldehyde, sulfur dioxide, and tobacco smoke. In addition to absorption of air pollutants, skin contact with chemicals such as metals (nickel, cobalt, chromium, cadmium, lead, platinum, copper, and mercury), some ingredients in cosmetics (fragrances, preservatives, paraphenylenediamine in hair and nail care products) could aggravate $\mathrm{AD}$, similarly with allergic contact dermatitis. Despite the increased use of food additives, the prevalence of adverse reactions attributed to their use is very low in the general population but seems higher in AD patients. Several chemical added in food to improve its organoleptic properties may be associated with non-allergic food hypersensitivity. Those additives include preservatives, antioxidants, artificial dyes, stabilizers, flavorings and taste enhancers, emulsifiers, and artificial sweeteners.

In summary, although the comprehensive effects of environmental chemicals as triggers of $\mathrm{AD}$ are still a subject of debate, eliminations of those with known correlation with $\mathrm{AD}$ might improve AD symptoms. Future studies should further investigate the specific mechanisms that contribute to these relationships for better management of $\mathrm{AD}$ in our daily life.

\section{REFERENCES}

1. Simpson, E.L. and Hanifin, J.M. (2006) Atopic dermatitis.
Med. Clin. North Am., 90, 149-167.

2. Kay, J., Gawkrodger, D.J., Mortimer, M.J. and Jaron, A.G. (1994) The prevalence of childhood atopic eczema in a general population. J. Am. Acad. Dermatol., 30, 35-39.

3. Williams, H.C. (2000) Epidemiology of atopic dermatitis. Clin. Exp. Dermatol., 25, 522-529.

4. Herd, R.M., Tidman, M.J., Prescott, R.J. and Hunter, J.A. (1996) Prevalence of atopic eczema in the community: the Lothian Atopic Dermatitis study. Br. J. Dermatol., 135, 18-19.

5. Tanei, R. (2009) Atopic dermatitis in the elderly. Inflammation Allergy Drug Targets, 8, 398-404.

6. Tanei, R. and Katsuoka, K. (2008) Clinical analyses of atopic dermatitis in the aged. J. Dermatol., 35, 562-569.

7. Williams, H.C., Burney, P.G., Hay, R.J., Archer, C.B., Shipley, M.J., Hunter, J.J., Bingham, E.A., Finlay, A.Y., Pembroke, A.C. and Graham-Brown, R.A. et al. (1994) The U.K. Working Party's Diagnostic Criteria for Atopic Dermatitis. I. Derivation of a minimum set of discriminators for atopic dermatitis. Br. J. Dermatol., 131, 383-396.

8. Lewis-Jones, M.S. and Finlay, A.Y. (1995) The children's Dermatology Life Quality Index (CDLQI): initial validation and practical use. Br. J. Dermatol., 132, 942-949.

9. Lewis-Jones, S. (2001) Atopic dermatitis in childhood. Hosp. Med., 62, 136-143.

10. Fivenson, D., Arnold, R.J., Kaniecki, D.J., Cohen, J.L., Frech, F. and Finlay, A.Y. (2002) The effect of atopic dermatitis on total burden of illness and quality of life on adults and children in a large managed care organization. J. Manag. Care Pharm., 8, 333-342.

11. Leung, D.Y. and Bieber, T. (2003) Atopic dermatitis. Lancet, 361, 151-160.

12. Williams, H.C. (2000) Epidemiology of atopic dermatitis. Clin. Exp. Dermatol., 25, 522-529.

13. Williams, H., Stewart, A., von Mutius, E., Cookson, W. and Anderson, H.R. (2008) Is eczema really on the increase worldwide? J. Allergy Clin. Immunol., 121, 947-954.

14. Strachan, D.P. (1989) Hay fever, hygiene, and household size. BMJ, 299, 1259-1260.

15. Akdis, C.A., Akdis, M., Bieber, T., Bindslev-Jensen, C., Boguniewicz, M., Eigenmann, P., Hamid, Q., Kapp, A., Leung, D.Y., Lipozencic, J., Luger, T.A., Muraro, A., Novak, N., Platts-Mills, T.A., Rosenwasser, L., Scheynius, A., Simons, F.E., Spergel, J., Turjanmaa, K., Wahn, U., Weidinger, S., Werfel, T. and Zuberbier, T. (2006) Diagnosis and treatment of atopic dermatitis in children and adults: European Academy of Allergology and Clinical Immunology/American Academy of Allergy, Asthma and Immunology/PRACTALL Consensus Report. J. Allergy Clin. Immunol., 118, 152-169.

16. Novak, N. and Simon, D. (2011) Atopic dermatitis - from new pathophysiologic insights to individualzed therapy. Allergy, 66, 830-839.

17. Suárez-Fariñas, M., Tintle, S.J., Shemer, A., Chiricozzi, A., Nograles, K., Cardinale, I., Duan, S., Bowcock, A.M., Krueger, J.G. and Guttman-Yassky, E. (2011) Nonlesional atopic dermatitis skin is characterized by broad terminal differentiation defects and variable immune abnormalities. J Allergy Clin. Immunol., 127, 954-964.

18. Eyerich, K. and Novak, N. (2013) Immunology of atopic eczema: overcoming the Th1/Th2 paradigm. Allergy, 68, 974- 
982.

19. Pastar, Z., Lipozencić, J. and Ljubojević, S. (2005) Etiopathogenesis of atopic dermatitis-an overview. Acta Dermatovenerol. Croat., 13, 54-62.

20. Bonness, S. and Bieber, T. (2007) Molecular basis of atopic dermatitis. Curr. Opin. Allergy Clin. Immunol., 7, 382-386.

21. Ober, C. and Yao, T.C. (2011) The genetics of asthma and allergic disease: a 21 st century perspective. Immunol. Rev., 242, 10-30

22. Lawson, V., Lewis-Jones, M.S., Finlay, A.Y., Reid, P. and Owens, R.G. (1998) The family impact of childhood atopic dermatitis: the Dermatitis Family Impact Questionnaire. Br. $J$. Dermatol., 138, 107-113.

23. Renz, H., Conrad, M., Brand, S., Teich, R., Garn, H. and Pfefferle, P.I. (2011) Allergicdiseases, gene-environment interactions. Allergy, 66 Suppl 95, 10-12.

24. McFadden, J.P., White, J.M., Basketter, D.A. and Kimber, I. (2009) Does hapten exposure predispose to atopic disease? The hapten-atopy hypothesis. Trends Immunol., 30, 67-74.

25. McFadden, J.P., Dearman, R.J., White, J.M., Basketter, D.A. and Kimber, I. (2011) The Hapten-Atopy hypothesis II: the 'cutaneous hapten paradox'. Clin. Exp. Allergy, 41, 327-337.

26. McFadden, J.P., Basketter, D.A., Dearman, R.J., Puangpet, P. and Kimber, I. (2014) Hapten-chemicalatopy hypothesis III: the potential role of airborne chemicals. Br. J. Dermatol., 170, 45-51.

27. Drasch, G., Schupp, I., Höfl, H., Reinke, R. and Roider, G. (1994) Mercury burden of human fetal and infant tissues. Eur. J. Pediatr., 153, 607-610.

28. Jung, K.H., Hsu, S.I., Yan, B., Moors, K., Chillrud, S.N., Ross, J., Wang, S., Perzanowski, M.S., Kinney, P.L., Whyatt, R.M., Perera, F.P. and Miller, R.L. (2012) Childhood exposure to fine particulate matter and black carbon and the development of new wheeze between ages 5 and 7 In an urban prospective cohort. Environ. Int., 45, 44-50.

29. Spira-Cohen, A., Chen, L.C., Kendall, M., Lall, R. and Thurston, G.D. (2011) Personal exposures to traffic-related air pollution and acute respiratory health among Bronx schoolchildren with asthma. Environ. Health Perspect., 119, 559-565.

30. Silverman, R.A. and Ito, K. (2010) Age-related association of fine particles and ozone with severe acute asthma in New York City. J. Allergy Clin. Immunol., 125, 367-373.

31. Montnemery, P., Nihlén, U., Göran Löfdahl, C., Nyberg, P. and Svensson, A. (2003) Prevalence of self-reported eczema in relation to living environment, socio-economic status and respiratory symptoms assessed in a questionnaire study. $B M C$ Dermatol., 3, 4.

32. Pénard-Morand, C., Raherison, C., Charpin, D., Kopferschmitt, C., Lavaud, F., Caillaud, D. and Annesi-Maesano, I. (2010) Long-term exposure to close-proximity air pollution and asthma and allergies in urban children. Eur. Respir. J., 36, 33-40.

33. Lee, Y.L., Su, H.J., Sheu, H.M., Yu, H.S. and Guo, Y.L. (2008) Traffic-related air pollution, climate, and prevalence of eczema in Taiwanese school children. J. Invest. Dermatol., 128, 2412-2420.

34. Morgenstern, V., Zutavern, A., Cyrys, J., Brockow, I., Koletzko, S., Krämer, U., Behrendt, H., Herbarth, O., von Berg, A., Bauer, C.P., Wichmann, H.E. and Heinrich, J. (2008)
Atopic diseases, allergic sensitization, and exposure to trafficrelated air pollution in children. Am. J. Respir. Crit. Care Med., 177, 1331-1337.

35. Jedrychowski, W., Perera, F., Maugeri, U., Mrozek-Budzyn, D., Miller, R.L., Flak, E., Mroz, E., Jacek, R. and Spengler, J.D. (2011) Effects of prenatal and perinatal exposure to fine air pollutants and maternal fish consumption on the occurrence of infantile eczema. Int. Arch. Allergy Immunol., 155, 275-281.

36. Just, A.C., Whyatt, R.M., Perzanowski, M.S., Calafat, A.M., Perera, F.P., Goldstein, I.F., Chen, Q., Rundle, A.G. and Miller, R.L. (2012) Prenatal exposure to butylbenzyl phthalate and early eczema in an urban cohort. Environ. Health Perspect., 120, $1475-1480$.

37. Kim, J., Kim, E.H., Oh, I., Jung, K., Han, Y., Cheong, H.K. and Ahn, K. (2013) Symptoms of atopic dermatitis are influenced by outdoor air pollution. J. Allergy Clin. Immunol., 132, 495-498.

38. Song, S., Lee, K., Lee, Y.M., Lee, J.H., Lee, S.I., Yu, S.D. and Paek, D. (2011) Acute health effects of urban fine and ultrafine particles on children with atopic dermatitis. Environ. Res., 111, 394-399.

39. Triggiani, M., Loffredo, S., Granata, F., Staiano, R.I. and Marone, G. (2011) Modulation of mast cell and basophil functions by benzene metabolites. Curr. Pharm. Des., 17, 38303835 .

40. Lehmann, I., Rehwagen, M., Diez, U., Seiffart, A., RolleKampczyk, U., Richter, M., Wetzig, H., Borte, M. and Herbarth, O. (2001) Enhanced in vivo IgE production and T cell polarization toward the type 2 phenotype in association with indoor exposure to VOC: results of the LARS study. Int. J. Hyg. Environ. Health, 204, 211-221.

41. Gillis, B., Gavin, I.M., Arbieva, Z., King, S.T., Jayaraman, S. and Prabhakar, B.S. (2007) Identification of human cell responses to benzene and benzene metabolites. Genomics, 90, 324-333.

42. Eberlein-Konig, B., Przybilla, B., Kuhnl, P., Pechak, J., Gebefugi, I., Kleinschmidt, J. and Ring, J. (1998) Influence of airborne nitrogen dioxide or formaldehyde on parameters of skin function and cellular activation in patients with atopic eczema and control subjects. J. Allergy Clin. Immunol., 101, 141-143.

43. Huss-Marp, J., Eberlein-König, B., Breuer, K., Mair, S., Ansel, A., Darsow, U., Krämer, U., Mayer, E., Ring, J. and Behrendt, H. (2006) Influence of short-term exposure to airborne Der $\mathrm{p} 1$ and volatile organic compounds on skin barrier function and dermal blood flow in patients with atopic eczema and healthy individuals. Clin. Exp. Allergy, 36, 338-345.

44. Herbarth, O., Fritz, G.J., Rehwagen, M., Richter, M., Roder, S. and Schlink, U. (2006) Association between indoor renovation activities and eczema in early childhood. Int. J. Hyg. Environ. Health, 209, 241-247.

45. Lee, J.H., Suh, J., Kim, E.H., Cho, J.B., Park, H.Y., Kim, J., Ahn, K., Cheong, H.K. and Lee, S.I. (2012) Surveillance of home environment in children with atopic dermatitis: a questionnaire survey. Asian Pac. Allergy, 2, 59-66.

46. Lee, J.Y., Seo, J.H., Kwon, J.W., Yu, J., Kim, B.J., Lee, S.Y., Kim, H.B., Kim, W.K., Kim, K.W., Shin, Y.J. and Hong, S.J. (2012) Exposure to gene-environment interactions before 1 year of age may favor the development of atopic dermatitis. 
Int. Arch. Allergy Immunol., 157, 363-371.

47. Bornehag, C.G., Sundell, J., Weschler, C.J., Sigsgaard, T., Lundgren, B., Hasselgren, M. and Hägerhed-Engman, L. (2004) The association between asthma and allergic symptoms in children and phthalates in house dust: a nested casecontrol study. Environ. Health Perspect., 112, 1393-1397.

48. Herberth, G., Bauer, M., Gasch, M., Hinz, D., Röder, S., Olek, S., Kohajda, T., Rolle-Kampczyk, U., von Bergen, M., Sack, U., Borte, M. and Lehmann, I. (2014) Maternal and cord blood miR-223 expression associates with prenatal tobacco smoke exposure and low regulatory T-cell numbers. J. Allergy Clin. Immunol., 133, 543-550.

49. Hinz, D., Bauer, M., Röder, S., Olek, S., Huehn, J., Sack, U., Borte, M., Simon, J.C., Lehmann, I. and Herberth, G. (2012) Cord blood Tregs with stable FOXP3 expression are influenced by prenatal environment and associated with atopic dermatitis at the age of one year. Allergy, 67, 380-389.

50. Lehmann, I., Thoelke, A., Rehwagen, M., Rolle-Kampczyk., U, Schlink, U., Schulz, R., Borte, M., Diez, U. and Herbarth, O. (2002) The influence of maternal exposure to volatile organic compounds on the cytokine secretion profile of neonatal T cells. Environ. Toxicol., 17, 203-210.

51. Wang, I.J., Chen, S.L., Lu, T.P., Chuang, E.Y. and Chen, P.C. (2013) Prenatal smoke exposure, DNA methylation, and childhood atopic dermatitis. Clin. Exp. Allergy, 43, 535-543.

52. Wang, I.J., Guo, Y.L., Lin, T.J., Chen, P.C. and Wu, Y.N. (2010) GSTM1, GSTP1, prenatal smoke exposure, and atopic dermatitis. Ann. Allergy Asthma Immunol., 105, 124-129.

53. Yi, O., Kwon, H.J., Kim, H., Ha, M., Hong. S.J., Hong, Y.C., Leem, J.H., Sakong, J., Lee, C.G., Kim, S.Y. and Kang, D. (2012) Effect of environmental tobacco smoke on atopic dermatitis among children in Korea. Environ. Res., 113, 40-45.

54. Jedrychowski, W., Perera, F., Maugeri, U., Mrozek-Budzyn, D., Miller, R.L., Flak, E., Mroz, E., Jacek, R. and Spengler, J.D. (2011) Effects of prenatal and perinatal exposure to fine air pollutants and maternal fish consumption on the occurrence of infantile eczema. Int. Arch. Allergy Immunol., 155, 275-281.

55. Herr, C.E., Dostal, M., Ghosh, R., Ashwood, P., Lipsett, M., Pinkerton, K.E., Sram, R. and Hertz-Picciotto, I. (2010) Air pollution exposure during critical time periods in gestation and alterations in cord blood lymphocyte distribution: a cohort of livebirths. Environ. Health, 9, 46.

56. Dong, G.H., Chen, T., Liu, M.M., Wang, D., Ma, Y.N., Ren, W.H., Lee, Y.L., Zhao, Y.D. and He, Q.C. (2011) Gender differences and effect of air pollution on asthma in children with and without allergic predisposition: northeast Chinese children health study. PLoS One, 6, e22470.

57. Takenaka, H., Zhang, K., Diaz-Sanchez, D., Tsien, A. and Saxon, A. (1995) Enhanced human IgE production results from exposure to the aromatic hydrocarbons from diesel exhaust: direct effects on B-cell IgE production. J. Allergy Clin. Immunol., 95, 103-115.

58. Inoue, K.I., Takano, H., Yanagisawa, R., Sakurai, M., Abe, S., Yoshino, S., Yamaki, K. and Yoshikawa, T. (2007) Effects of components derived from diesel exhaust particles on lung physiology related to antigen. Immunopharmacol. Immunotoxicol., 29, 403-412.

59. Martin, S.F. (2012) Contact dermatitis: from pathomecha- nisms to immunotoxicology. Exp. Dermatol., 21, 382-389.

60. Thyssen, J.P., Linneberg, A., Menné, T. and Johansen, J.D. (2007) The epidemiology ofcontact allergy in general population - prevalence and main findings. Contact Dermatitis, 57, 287-299.

61. Basko-Plluska, J.L., Thyssen, J.P. and Schalock, P.C. (2011) Cutaneous and systemic hypersensitivity reactions to metallic implants. Dermatitis, 22, 65-79.

62. Koller, L.D. (1980) Immunotoxicology of heavy metals. Int. J. Immunopharmacol., 2, 269-279.

63. Costa, M., Cantoni, O., de Mars, M. and Swartzendruber, D.E. (1982) Toxic metal produce an S-phase-specific cell cycle block. Res. Commun. Chem. Pathol. Pharmacol., 38, 405-419.

64. Kieć-Świerczyńska, M., Kręcisz, B., Chomiczewska, D. and Sobala, W. (2012) Trends inallergy to the 10 most frequent contact allergens in patients examinedat the Nofer Institute, Lodz, Poland in 1996-2009. Post. Dermatol. Alergol., 1, 1924.

65. Garg, S., McDonagh, A.J. and Gawkrodger, D.J. (2009) Ageand sex-relatedvariations in allergic contact dermatitis to common allergens. Contact Dermatitis, 61, 46-47.

66. Friberg, L., Kullman, L., Lind, B. and Nylander, M. (1986) Mercury in the central nervous system in relation to amalgam fillings. Lakartidringen, 83, 519-522.

67. Nylander, M. (1986) Mercury in pituitary glands of dentists. Lancet, 1, 442.

68. Glomski, C.A., Brody, H. and Pillay, S.K. (1971) Distribution and concentration of mercury in autopsy specimens of human brain. Nature, 232, 200-201.

69. Klimańska, M., Żmudzińska, M., Jenerowicz, D. and Czarnecka-Operacz, M. (2011) The importance of exposure to contact allergens in patients withallergic contact dermatitis. Post. Dermatol. Alergol., 3, 203-211.

70. Ortiz, K.J. and Yiannias, J.A. (2004) Contact dermatitis to cosmetics, fragrances, and botanicals. Dermatol. Ther, 17, 264-271.

71. Kind, F., Scherer, K. and Bircher, A.J. (2012) Contact dermatitis to paraphenylenediaminein hair dye following sensitization to black hennatattoos - an ongoing problem. J. Dtsch. Dermatol. Ges., 10, 572-578.

72. Yim, E., Baquerizo Nole, K.L. and Tosti, A. (2014) Contact dermatitis caused by preservatives. Dermatitis, 25, 215-231.

73. Lever, R. (2001) The role of food in atopic eczema. J. Am. Acad. Dermatol., 45(Suppl 1), S57-60.

74. Lack, G. (2008) Clinical practice. Food allergy. $N$ Engl. J. Med., 359, 1252-1260.

75. Hanifin, J.M. (1997) Critical evaluation of food and mite allergy in the management of atopic dermatitis. J. Dermatol., 24, 495-503.

76. Worth, A. and Sheikh, A. (2010) Food allergy and atopic eczema. Curr. Opin. Allergy Clin. Immunol., 10, 226-230.

77. Bjorkstén, B. (2005) Genetic and environmental risk factors for the development of food allergy. Curr. Opin. Allergy Clin. Immunol., 5, 249-253.

78. Rosińska-Więckowicz, A. and Czarnecka-Operacz, M. (2011) Disease extentand severity in patients with atopic dermatitis and food allergy. Post. Dermatol. Alergol., 5, 382-388.

79. Zaknun, D., Schroecksnadel, S., Kurz, K. and Fuchs, D. (2012) Potential role ofantioxidant food supplements, preser- 
vatives and colorants in thepathogenesis of allergy and asthma. Int. Arch. Allergy Immunol., 157, 113-124.

80. Young, E., Patel, S., Stoneham, M., Rona, R. and Wilkinson, J.D. (1987) The prevalence of reaction to food additives in a survey population. J. R. Coll. Physicians Lond., 21, 241-247.

81. Fuglsang, G., Madsen, C., Saval, P. and Osterballe, O. (1993) Prevalence of intolerance to food additives among Danish school children. Pediatr. Allergy Immunol., 4, 123-129.

82. Fuglsang, G., Madsen, G., Halken, S., Jørgensen, S., Oster- gaard, P.A. and Osterballe, O. (1994) Adverse reactions to food additives in children with atopic symptoms. Allergy, 49, 31-37.

83. Park, H.W., Park, C.H., Park, S.H., Park, J.Y., Park, H.S., Yang, H.J., Ahn, K.M., Kim, K.H., Oh, J.W., Kim, K.E., Pyun, B.Y., Lee, H.B. and Min, K.U. (2008) Dermatologic adverse reactions to 7 common food additives in patients with allergic diseases: a double-blind, placebo-controlled study. $J$. Allergy Clin. Immunol., 121, 1059-1061. 